\title{
Identification of miR-125a-5p as a tumor suppressor of renal cell carcinoma, regulating cellular proliferation, migration and apoptosis
}

\author{
DUQUN CHEN ${ }^{1-3}$, YIFAN LI $^{1-3}$, ZHENGMING SU ${ }^{1,2,4}$, ZUHU YU $^{1-3}$, WENSHUI YU $^{1,2,4}$, \\ YUCHI LI ${ }^{1,2,4}$, YAOTING GUI ${ }^{2}$, SHANGQI YANG ${ }^{1,2}$ and YONGQING LAI ${ }^{1,2}$ \\ ${ }^{1}$ Department of Urology, Peking University Shenzhen Hospital; ${ }^{2}$ The Guangdong and Shenzhen Key Laboratory of \\ Male Reproductive Medicine and Genetics, Peking University Shenzhen Hospital, Institute of Urology of \\ Shenzhen PKU-HKUST Medical Center, Shenzhen, Guangdong 518036; ${ }^{3}$ Department of Urology, \\ Anhui Medical University, Hefei, Anhui 230032; ${ }^{4}$ Department of Urology, Shantou University \\ Medical College, Shantou, Guangdon 515041, P.R. China
}

Received April 3, 2014; Accepted July 22, 2014

DOI: $10.3892 / \mathrm{mmr} .2014 .2848$

\begin{abstract}
R-125a-5p has been previously described as a tumor suppressor in numerous malignancies, however the expression and function of miR-125a-5p in renal cell carcinoma ( $R C C$ ) remains to be elucidated. In the present study, to explore the potential role of $\mathrm{miR}-125 \mathrm{a}-5 \mathrm{p}$ in $\mathrm{RCC}$, quantitative polymerase chain reaction was used to determine the expression levels of miR-125a-5p in renal cancer tissues. The influence of miR-125a-5p on cell proliferation, migration and apoptosis was also determined, using an MTT assay, a wound scratch assay and flow cytometry, respectively. The expression of miR-125a-5p was shown to be decreased in RCC and the restoration of miR-125a-5p by synthetic mimics was shown to suppress cell proliferation and migration, and induce apoptosis. The present results indicate that miR-125a-5p may function as a tumor suppressor in RCC. The present study is, to the best of our knowledge, the first to demonstrate the downregulation of miR-125a-5p in RCC, and to show the role it has in affecting cellular proliferation, migration and apoptosis. Further research is needed to define the target genes of miR-125a-5p and explore the potential of miR-125a-5p as a diagnostic or a prognostic biomarker for RCC.
\end{abstract}

\section{Introduction}

Renal cell carcinoma (RCC) is a highly vascularized tumor which accounts for $\sim 3 \%$ of all malignancies in adults, and has

\footnotetext{
Correspondence to: Professor Yongqing Lai or Dr Shangqi Yang, Department of Urology, Peking University Shenzhen Hospital, Institute of Urology of Shenzhen PKU-HKUST Medical Center, 1120 Lianhua Road, Shenzhen, Guangdong 518036, P.R. China E-mail: yqlord@163.com

E-mail: yangshangqi88@yahoo.com.cn
}

Key words: miR-125a-5p, tumor suppressor, renal cell carcinoma the highest mortality rate of all urological malignancies $(1,2)$. Recently estimated cancer statistics showed that both the incidence, and the mortality rate of RCC were among the 10 leading cancers in the USA, with $>65150$ new cases and $>8,780$ mortalities recorded in 2013 (3). RCC is a relatively asymptomatic disease and $30 \%$ of all patients exhibit metastatic disease at the time of initial presentation (4). When left untreated, the five-year survival rate for metastatic RCC (mRCC) is $2 \%$, and the median survival time is $\sim 8$ months (5). It is therefore crucial to identify novel molecular biomarkers which may be used for early detection and targeted therapy, based on the developing knowledge of the tumorigenesis mechanisms of RCC.

MicroRNAs (miRNAs) are a class of non-coding RNAs, $\sim 22$ nucleotides (nt) in length, which are involved in the control of gene expression by targeting mRNAs for either translational repression or degradation (6,7). A previous study has shown that miRNAs have important roles in various cellular processes, including proliferation, differentiation, metabolism and survival (8). Deregulation of miRNAs can alter normal cell growth and development, leading to numerous disorders, including cancers (8). To date, aberrant expression or mutation of miRNAs has been observed in numerous types of human cancer. It is estimated that $>60 \%$ of human protein-coding genes are under selective pressure to maintain pairing to miRNAs (9), confirming the significance of miRNAs in the gene regulatory network.

Recently, miR-125a-5p has been reported to function as a tumor suppressor in malignancies of the breast (10-12), lung (12), liver (13) and the central nervous system (14). However, the function and clinical significance of miR-125a-5p in RCC has yet to be explored (15). To determine whether miR-125a-5p is important for the tumorigenesis of RCC, human renal cancer and paired normal tissues were collected and compared for miR-125a-5p expression levels, using quantitative polymerase chain reaction (qPCR). Furthermore, the impact of miR-125a-5p on cell proliferation, migration and apoptosis was analyzed by transfection of synthesized miR-125a-5p mimics into RCC cell lines. 


\section{Materials and methods}

Sample collection and RNA isolation. The RCC tissues and paired adjacent normal tissues used throughout the present study were collected from hospitals of the Guangdong, Hunan and Anhui provinces. Written informed consent was obtained from all of the patients. Collection and use of the samples was reviewed and approved by the Ethics Committees of the local hospital and Peking University Shenzhen Hospital. Fresh RCC and adjacent normal tissues, located $2.0 \mathrm{~cm}$ outside of visible RCC lesions, were immersed in RNAlater ${ }^{\circledR}$ (Qiagen, Hilden, Germany) for $30 \mathrm{~min}$ following dissection, and then stored at $-80^{\circ} \mathrm{C}$ until further use. All tissue samples were reviewed and classified by hematoxylin \& eosin (H\&E) staining and the 2009 American Joint Committee on Cancer (AJCC) staging system. Total RNA of each sample was isolated using TRIzol ${ }^{\circledR}$ reagent (Invitrogen Life Technologies, Carlsbad, CA, USA), and purified using an RNeasy ${ }^{\circledR}$ Maxi kit (Qiagen), to the manufacturer's instructions. The clinical and pathological characteristics of the 48 RCC patients are shown in Table 1. The ages of the patients ranged from 29-76 years old, with a median age of 52 .

Analysis of miR-125a-5p expression in RCC tissues and paired normal tissues by qPCR. qPCR was used to detect the expression levels of miR-125a-5p in the 48 RCC tissues and paired adjacent normal tissues. A total RNA volume of $1 \mu \mathrm{g}$ from each sample was isolated for reverse transcription using an miScript Reverse Transcription kit (Qiagen), according to the manufacturer's instructions, in order to obtain the cDNA template. The qPCR was performed using a Light Cycle 480 Fluorescent Quantitative PCR System (Takara Bio, Inc., Otsu, Japan) with the miScript SYBR Green PCR kit (Qiagen), U6 was used as an internal control. The reaction mixture contained: $2 \mu \mathrm{l}$ cDNA template, $1 \mu 1$ specific microRNA primer, $2 \mu 1$ 10x miScript Universal Primer, $10 \mu 1$ 2x QuantiTect SYBR Green PCR Master Mix, and RNase-free water (Takara Bio, Inc.). The following primers were used in the qPCR reaction: $\mathrm{miR}-125 \mathrm{a}-5 \mathrm{p}$, forward 5'-TCCCTGAGACCCTTTAAACTGTGA-3', and the reverse primer used was provided by the miScript SYBR Green PCR kit; U6, forward 5'-CTCGCTTCGGCAGCACA-3' and reverse 5'-ACGCTTCACGAATTTGCGT-3'. The amplification conditions were: $95^{\circ} \mathrm{C} 2 \mathrm{~min}$, followed by $95^{\circ} \mathrm{C} 15 \mathrm{sec}, 58^{\circ} \mathrm{C} 30 \mathrm{sec}$ and $72^{\circ} \mathrm{C} 30 \mathrm{sec}$, for 40 cycles.

Cell culture and transfection. ACHN and 786-O renal carcinoma cell lines obtained from the laboratory of the Institute of Urology of Shenzhen PKU-HKUST Medical Center (Shenzhen, China) were cultured in Dulbecco's Modified Eagle's Medium (Thermo Fisher Scientific, Waltham, MA, USA), supplemented with $10 \%$ fetal bovine serum (Invitrogen Life Technologies), in a humidified incubator containing $5 \% \mathrm{CO}_{2}$. For restoration of miR-125a-5p in RCC tissues with endogenously downregulated miR-125a-5p, synthesized miR-125a-5p mimics (GenePharma, Shanghai, China) were transfected into the cells using Lipofectamine ${ }^{\circledR} 2000$ (Invitrogen Life Technologies), according to the manufacturer's instructions. The cells were harvested and total RNA was isolated for qPCR analysis $24 \mathrm{~h}$ after transfection.
Table I. Clinical and pathological features of patients with renal cell carcinoma.

\begin{tabular}{|c|c|}
\hline Variables & No. of cases \\
\hline Total & 48 \\
\hline \multicolumn{2}{|l|}{ Age (years) } \\
\hline$>52$ & 29 \\
\hline$<52$ & 19 \\
\hline \multicolumn{2}{|l|}{ Gender } \\
\hline Male & 30 \\
\hline Female & 18 \\
\hline \multicolumn{2}{|c|}{ Histological type } \\
\hline Clear cell & 39 \\
\hline Papillary & 9 \\
\hline \multicolumn{2}{|l|}{ pT-stage } \\
\hline $\mathrm{T} 1$ & 27 \\
\hline $\mathrm{T} 2$ & 19 \\
\hline T3 and T4 & 2 \\
\hline \multicolumn{2}{|c|}{ Fuhrman grade } \\
\hline $\mathrm{I}$ & 15 \\
\hline II & 22 \\
\hline III & 8 \\
\hline IV & 3 \\
\hline \multicolumn{2}{|c|}{ AJCC clinical stages } \\
\hline $\mathrm{I}$ & 27 \\
\hline II & 18 \\
\hline III+IV & 3 \\
\hline
\end{tabular}

pT, primary tumor; AJCC, American Joint Committee on Cancer.

Assessment of cellular proliferation by MTT assay. Cellular proliferation was measured using an MTT assay kit (Sigma, St Louis, MO, USA). The renal cancer cells $\left(\sim 5 \times 10^{3}\right.$ cells $)$ were seeded into 96-well culture plates and transfected with either miR-125a-5p mimics or a negative control. The negative control was set up with medium only. At $0,24,48$ or $72 \mathrm{~h}$ after transfection, the cells were incubated with $20 \mu \mathrm{l}$ MTT reagent $\left(5 \mathrm{mg} / \mathrm{ml}\right.$ ) for $4 \mathrm{~h}$ at $37^{\circ} \mathrm{C}$. Following the removal of MTT, the cells were incubated in dimethyl sulfoxide (150 $\mu \mathrm{l}$; Sigma) with shaking for $10 \mathrm{~min}$ at room temperature. The optical density (OD) was measured using a microplate reader (Model 680; Bio-Rad, Hercules, CA, USA) at a dual wavelength of 490/630 nm.

Wound scratch assay. The migratory ability of renal cancer cells was assessed using a wound scratch assay. In this assay $\sim 250,000$ cells were seeded in a 12-well dish followed by transfection after $24 \mathrm{~h}$ with miR-125a-5p mimics or the negative control (both 80 pmol) using Lipofectamine 2000. After $5 \mathrm{~h}$ of transfection, a vertical wound was made using a sterile $10 \mu \mathrm{l}$ pipette tip and markers were assigned to allow for observation of the cells in the correct location. Subsequently, the cells were rinsed three times with phosphate-buffered saline 
and incubated at $37^{\circ} \mathrm{C}$. Images of the wound scratches were taken immediately as well as following a $24 \mathrm{~h}$ incubation. The migration distance $(\mu \mathrm{m})$ was assessed using a standard caliper. The experiments were performed in triplicate, and analyzed double-blind by at least two observers.

Flow cytometry. For the apoptosis assay, $\sim 300,000$ renal cancer cells were cultured in six-well plates at $37^{\circ} \mathrm{C}$ and transfected with either miR-125a-5p mimics or the negative control within $24 \mathrm{~h}$. After $48 \mathrm{~h}$ transfection, the cells, including floating cells, were harvested, washed twice with cold PBS and resuspended in $100 \mu \mathrm{l} 1 \mathrm{x}$ binding buffer (Invitrogen Life Technologies). Subsequently, $3 \mu 1$ of propidium iodide (PI) and $5 \mu \mathrm{l}$ of Annexin V-fluorescein isothiocyanate (Invitrogen Life Technologies) were added to each cell suspension. The fluorescence of the stained cells was analyzed by flow cytometry (Beckman Coulter, Miami, FL, USA) within 30 min following staining, according to the manufacturer's instructions.

Statistical analyses. SPSS version 17.0 statistical software (SPSS, Inc., Chicago, IL, USA) was used for statistical analyses. Statistical significance was determined with the Student's t-test and the paired t-test. A $\mathrm{P}<0.05$ was considered to indicate a statistically significant difference.

\section{Results}

miR-125a-5p expression is downregulated in 48 paired $R C C$ tissues, as compared with adjacent tissues. A previous study showed miR-125a-5p to be downregulated in RCC tissues, as determined by miRNA expression profiling (16). In order to confirm the results of the former study, the expression levels of miR-125a-5p, in 48 RCC tissues and paired normal tissues, were analyzed using qPCR. The relative expression of miR-125a-5p [Log2 Ratio] is shown in Fig. 1A. The present results confirmed that miR-125a-5p expression was significantly downregulated in renal cancer tissues, as compared with the expression levels in the paired adjacent normal tissues $(\mathrm{P}<0.01$, Fig. 1B).

Transfection efficiency. To analyze the function of miR-125a-5p in RCC, miR-125a-5p mimics and a negative control were transfected into ACHN and 786-O renal cancer cell lines. The relative expression of $\mathrm{miR}-25 \mathrm{a}-5 \mathrm{p}$, following transfection, was determined by qPCR. The expression levels in the ACHN and 786-O cells transfected with the mimics were 163.2 and 134.6, respectively (Fig. 1B).

Overexpression of miR-125a-5p suppresses cell proliferation. The MTT assay was used to determine the effect of miR-125a-5p mimics on the proliferation of renal cancer cells. The OD values of the miR-125a-5p mimics and the negative control groups, were measured at $0,24,48$ and $72 \mathrm{~h}$ after transfection. The outcomes revealed that ACHN cell proliferation was decreased by $6.075,13.907$ and $22.461 \%$ (all $\mathrm{P}<0.05$ ), and the proliferation of 786-O cells was decreased by $6.168,11.438$, and $20.642 \%$ (all $\mathrm{P}<0.05$ ) at 24,48 and $72 \mathrm{~h}$ after transfection, respectively, as compared with $0 \mathrm{~h}$. The results indicated that the upregulation of miR-125a-5p expression may suppress the proliferation of renal cancer cells (Fig. 2).
MiR-125a-5p mimics inhibit cell migration. The effects of upregulation of miR-125a-5p expression on cellular migration in renal cancer cells was observed by a wound scratch assay. As shown in Fig. 3, the wound widths of the cells transfected with a negative control were significantly narrower, as compared with the wound widths in the miR-125a-5p mimics group $(\mathrm{P}<0.05)$. These results suggested that the upregulation of miR-125a-5p inhibited the migratory ability of the renal cancer cells (Fig. 3).

Restoration of miR-125a-5p induces cellular apoptosis. To determine the impact of miR-125a-5p on renal cancer cell apoptosis, a flow cytometry assay was performed to detect the rate of apoptosis in the renal cancer cells $48 \mathrm{~h}$ after transfection with miR-125-5p mimics or a negative control. The results revealed that the apoptotic rates of $\mathrm{ACHN}$ transfected with miR-125a-5p mimics and negative control group were 8.8 and $5.1 \%$ respectively, whereas the apoptotic rates of $786-\mathrm{O}$ cells were 7.5 and $3.4 \%(\mathrm{P}<0.01)$, therefore suggesting that the restoration of miR-125a-5p expression may accelerate the rate of apoptosis of renal cancer cells (Fig. 4).

\section{Discussion}

miRNAs are short, single-stranded RNAs which are associated with gene regulation, at both the transcriptional and translational level, by base-pairing to complementary mRNA sequences in their target genes (17). MiRNAs have diverse functions and are involved in a variety of biochemical processes, including cellular differentiation, proliferation, apoptosis, metabolism and disease, including cancer (18). Deregulation of miRNAs is emerging as a major aspect of cancer etiology, and has previously been confirmed to be capable of promoting cancer initiation and progression in vivo (19), including in RCC. Numerous miRNAs have been confirmed to be upregulated in RCC, including miR-21, miR-210 and miR-155 (18,19), while miR-127-3p, miR-145 and miR-126 have been shown to be significantly downregulated and correlated with relapse-free survival in patients with nonmetastatic RCC (20). Furthermore, serum miRNA levels have been associated with RCC and may be used as potential biomarkers; including miR-210 for early detection (19), miR-378 and miR-451 for diagnosis (21), and miR-122, miR-514, miR-192 and miR-215 for prognosis prediction and as therapeutic targets $(18,22)$.

MiR-125a-5p has been described as a tumor suppressor in numerous human cancers (10-13). Previous research has demonstrated that miR-125a expression is downregulated in certain cancers and it may reduce the expression levels of several oncogenes, for example, human epidermal growth factor receptor-2 (HER-2), podoplanin membrane sialo-glycoprotein, matrix metalloproteinase 11 and vascular endothelial growth factor A (13). However, the role of miR-125a in RCC remains unclear.

To determine whether miR-125a-5p is involved in RCC tumorigenesis, qPCR was used to quantify the miR-125a-5p expression levels in $48 \mathrm{RCC}$ tissues and paired normal tissues. The effects of miR-125a-5p on cell migration, proliferation and apoptosis were also analyzed by transfection of RCC cell lines with synthetic miR-125a-5p mimics. 


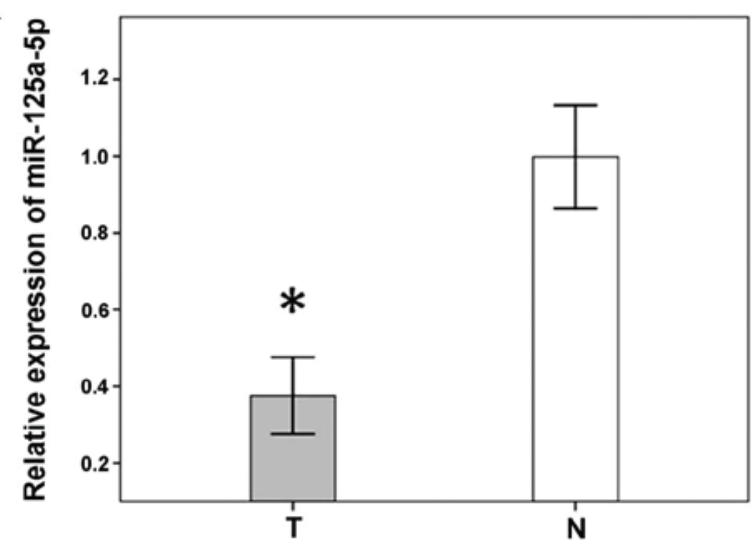

B

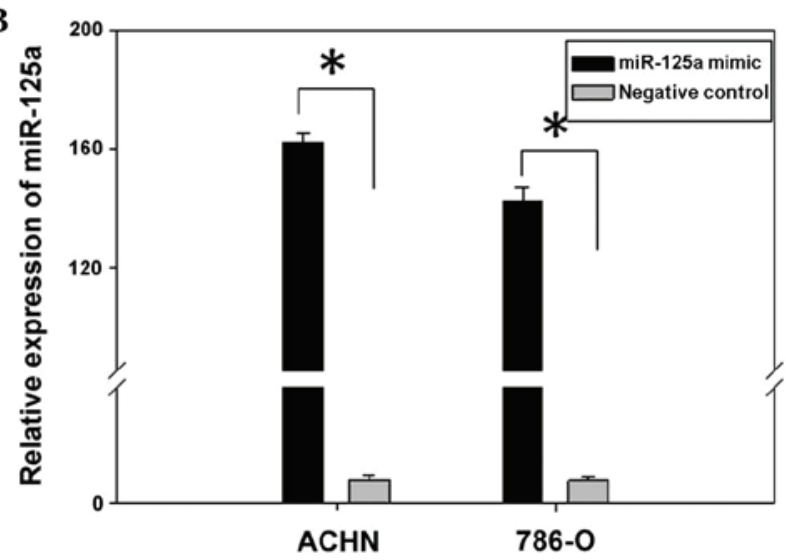

Figure 1. (A) Relative expression levels of miR-125a-5p in 48 paired renal cell carcinoma tissues and adjacent normal tissues, as analyzed by quantitative polymerase chain reaction. (B) Relative expression levels of miR-125a-5p in ACHN and 786-O renal cancer cells, $24 \mathrm{~h}$ after transfection with either a negative control, or miR-125a-5p mimics. Values are expressed as the mean \pm standard deviation of three independent experiments. ${ }^{*} \mathrm{P}<0.05$. T, renal cell carcinoma tissues; $\mathrm{N}$, adjacent normal tissues.

A

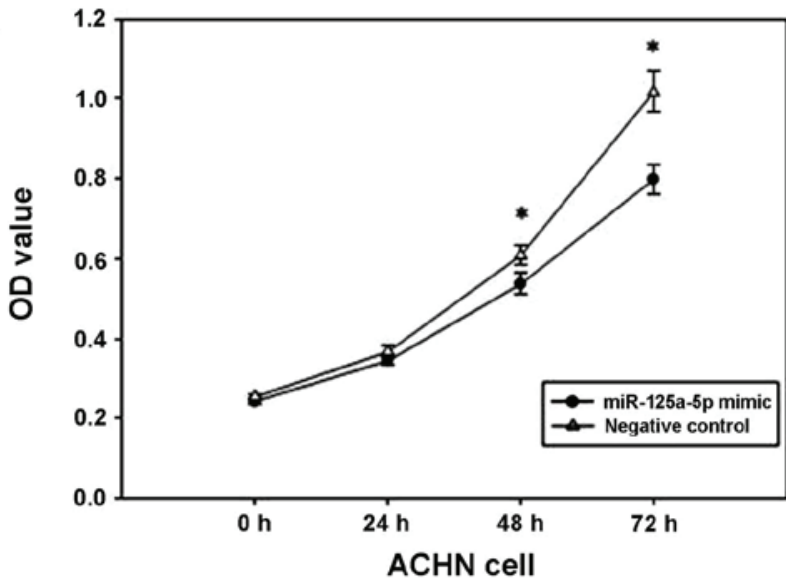

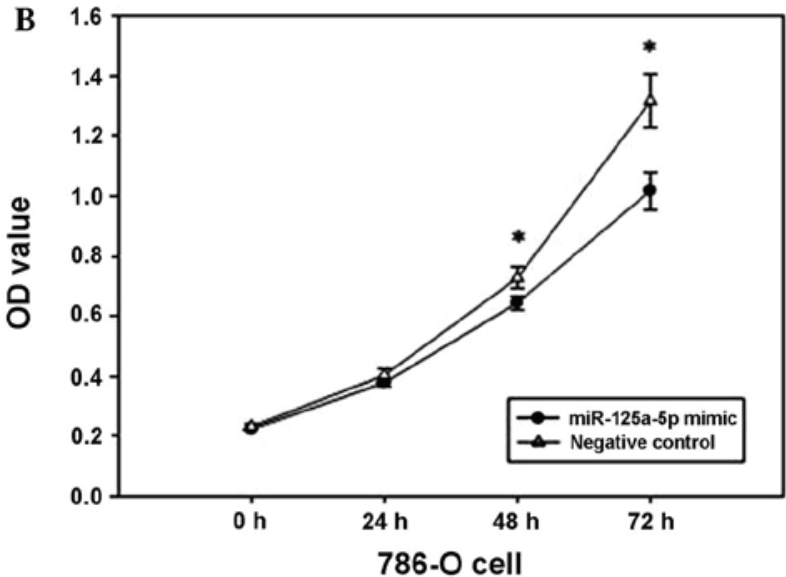

Figure 2. Analysis of cell proliferation by MTT assay in 786-O and ACHN renal cancer cells transfected with miR-125a-5p mimics or negative control. (A) Cell proliferation of ACHN cells. (B) Cell proliferation of 786-O cells. Values are expressed as the mean \pm standard error. "P<0.05. OD, optical density; h, hours.

The present results showed that miR-125a-5p expression was significantly downregulated in RCC tissues, as compared with the expression levels in paired normal renal tissues. Transfection of miR-125a-5p mimics into 786-O and ACHN renal cancer cell lines inhibited cellular proliferation, migration and induced apoptosis, as compared with the negative control group, indicating that miR-125a-5p may be characterized as a tumor suppressor in RCC by inhibiting cellular proliferation and migration, and promoting cellular apoptosis. The further study of miR-125a-5p target genes may provide a deeper understanding of the molecular mechanisms of tumorigenesis in RCC.

Previous studies have demonstrated that miRNAs can be detected in the circulation and may serve as potential biomarkers for numerous diseases, including cancer. It was previously reported that miR-125a-5p could serve as a biomarker for rheumatoid arthritis (23), and it has been associated with a worsened disease progression of Hepatitis $B$ virus chronic infection (24). Alongside miR-125a-3p, miR-125a-5p has shown to be a useful prognostic marker in gastric cancer $(25,26)$. Whether miR-125a-5p can be used as a potential biomarker for the early detection and prognosis prediction of RCC requires further investigation.

Due to the involvement of miRNAs in cancer development, the manipulation of cellular miRNA levels has emerged as a potential strategy for therapeutic intervention (10). Overexpressed HER-2 is observed in breast and gastric cancers (27). Previous studies have demonstrated the improvement of survival rates in patients treated with HER-2-targeted therapy $(27,28)$ and the anti-HER-2 therapy trastuzumab has been used as a first line treatment for HER-2-positive cancers in the clinical practice (29). Previous research has revealed HER-2 to be a direct target of miR-125a-5p. Nishida et al (25) revealed that transfection with miR-125a mimics suppressed the proliferation of gastric cancer cells. The effects of the mimics were enhanced when used in combination with trastuzumab. These results indicate that miR-125a-5p mimics alone, or in combination with trastuzumab, may be a novel therapeutic approach against gastric cancer. Further research on the role of miR-125a-5p in the tumorigenesis of RCC may explore its potential for targeted therapy. 

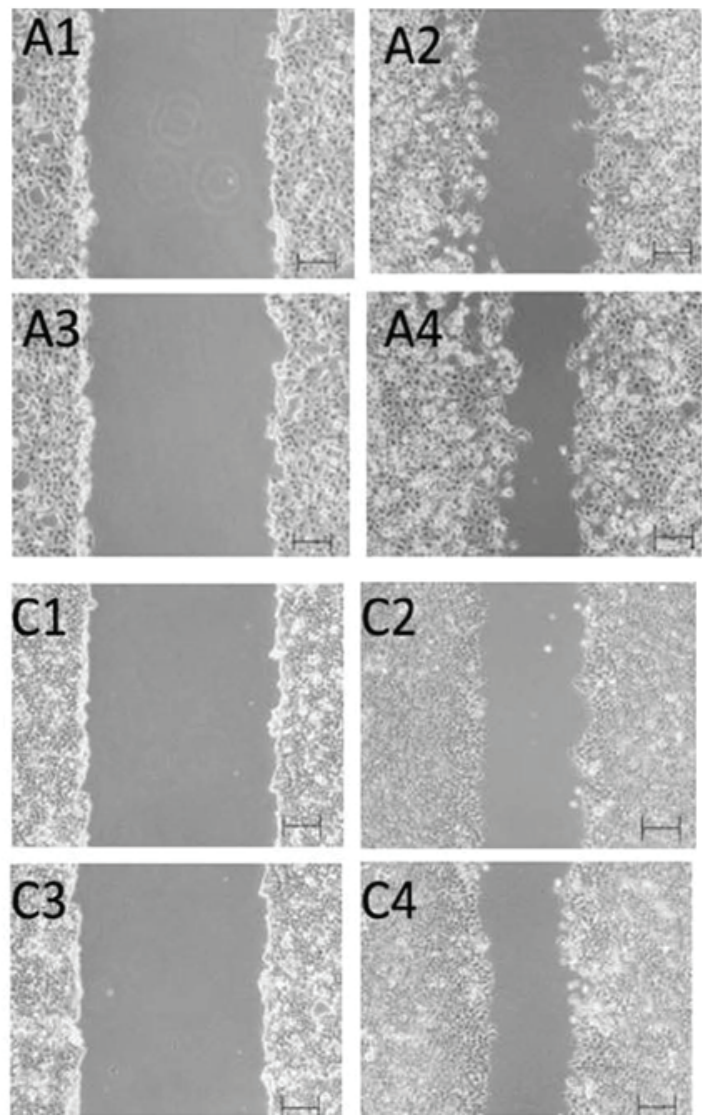
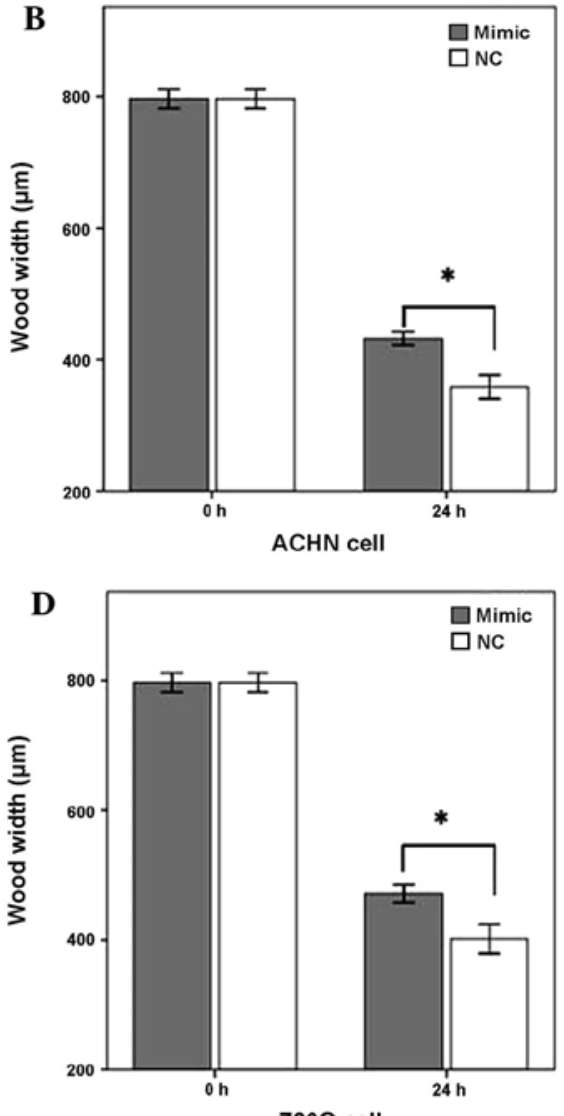

Figure 3. Wound scratch assay for ACHN and 786-O renal cancer cells, $24 \mathrm{~h}$ after transfection with miR-125a-5p mimics or negative control. (A1 and 2) Images of ACHN cells transfected with miR-125a-5p mimics at the wound site, (A1) $0 \mathrm{~h}$ and (A2) $24 \mathrm{~h}$ after its generation. (A3 and 4) Images of the ACHN cells transfected with negative control at the wound site, (A3) $0 \mathrm{~h}$ and (A4) $24 \mathrm{~h}$ after its generation. (B) Comparison of the wound widths ( $\mu \mathrm{m}$ ) in ACHN cells transfected with miR-125a-5p mimics or a negative control. (C1 and C2) Images of the 786-O cells transfected with miR-125a-5p mimics at the wound site, (C1) $0 \mathrm{~h}$ and (C2) $24 \mathrm{~h}$ after its generation. (C3 and 4) Images of the 786-O cells transfected with negative control (C3) $0 \mathrm{~h}$ and (C4) $24 \mathrm{~h}$ after its generation.(D) Comparison of the wound widths $(\mu \mathrm{m})$ in 786-O cells transfected with miR-125a-5p mimics or negative control. Values are expressed as the mean \pm standard error. ${ }^{*} \mathrm{P}<0.05$. NC, negative control.
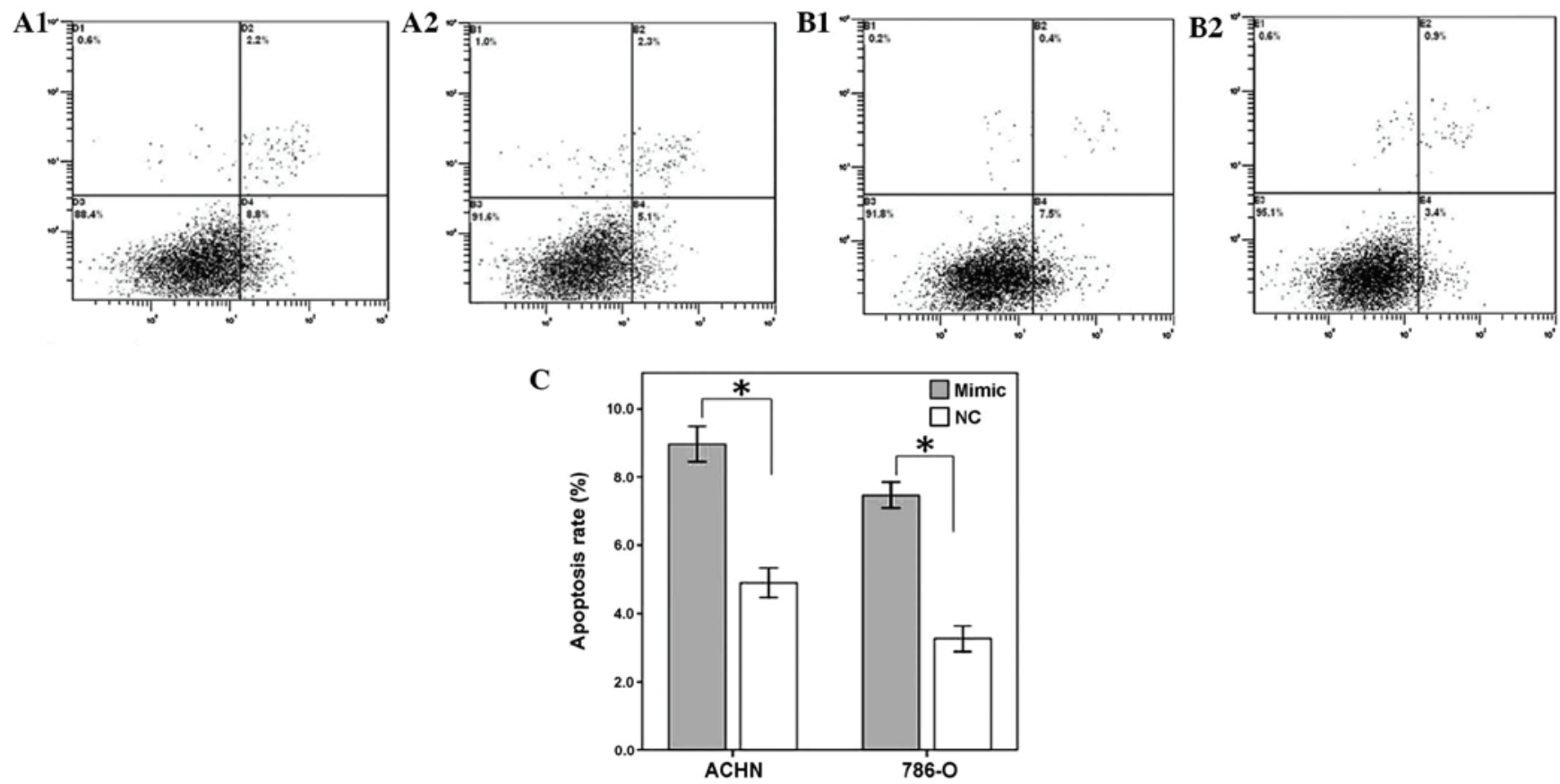

Figure 4. Analysis of the rate of apoptosis by flow cytometry in ACHN and 786-O renal cancer cells following transfection with miR-125a-5p mimics or negative control. (A1 and 2) ACHN cells transfected with (A1) miR-125a-5p mimics or (A2) negative control, respectively. (B1 and 2) 786-O cells transfected with (B1) miR-125a-5p mimics or (B2) negative control, respectively. (C) Comparison of ACHN and 786-O cell apoptosis rates following transfection with miR-125a-5p mimics and negative control. Values are expressed as the mean \pm standard error. $\mathrm{P}<0.05$. NC, negative control. 
In conclusion, the present study was, to the best of our knowledge, the first to reveal the downregulation of miR-125a-5p expression in RCC and to demonstrate its significant role in affecting cellular proliferation, migration and apoptosis. Further research is needed to define the target genes of miR-125a-5p in RCC and to explore the potential use of miR-125a-5p in early detection, prognosis prediction and as a targeted therapy for RCC.

\section{Acknowledgements}

This work was supported by the National Natural Science Foundation of China(no.81101922), Medical Scientific Research Foundation of Guangdong Province of China (no. A2012584 and A2013606), Science and Technology Development Fund Project of Shenzhen (no. JCYJ20130402114702124) and Shenzhen Science and Technology Project (no. 201302050).

\section{References}

1. Cairns P: Renal cell carcinoma. Cancer Biomark 9: 461-473, 2010.

2. McLaughlin JK, Lipworth L and Tarone RE: Epidemiologic aspects of renal cell carcinoma. Semin Oncol 33: 527-533, 2006.

3. Siegel R, Naishadham D and Jemal A: Cancer statistics, 2013. CA Cancer J Clin 63: 11-30, 2013.

4. Chow WH and Devesa SS: Contemporary epidemiology of renal cell cancer. Cancer J 14: 288-301, 2008.

5. Rasmussen F: Metastatic renal cell cancer. Cancer Imaging 13: 374-380, 2013.

6. Wu L and Belasco JG: Micro-RNA regulation of the mammalian lin-28 gene during neuronal differentiation of embryonal carcinoma cells. Mol Cell Biol 25: 9198-9208, 2005.

7. Vaz C, Ahmad HM, Sharma P, et al: Analysis of microRNA transcriptome by deep sequencing of small RNA libraries of peripheral blood. BMC Genomics 11: 288, 2010.

8. Lin Y, Zeng Y, Zhang F, et al: Characterization of microRNA expression profiles and the discovery of novel microRNAs involved in cancer during human embryonic development. PLoS One 8: e69230, 2013.

9. Friedman RC, Farh KK, Burge CB and Bartel DP: Most mammalian mRNAs are conserved targets of microRNAs. Genome Res 19: 92-105, 2009.

10. Wang S, Huang J, Lyu H, et al: Functional cooperation of miR-125a, miR-125b, and miR-205 in entinostat-induced dowregulation of erbB2/erbB3 and apoptosis in breast cancer cells. Cell Death Dis 4: e556, 2013.

11. LiW,Duan R, Kooy F, etal:Germline mutation of microRNA-125a is associated with breast cancer. J Med Genet 46: 358-360, 2009.
12. Lee $\mathrm{CH}$, Kuo WH, Lin CC, et al: MicroRNA-regulated protein-protein interaction networks and their functions in breast cancer. Int J Mol Sci 14: 11560-11606, 2013.

13. Bi Q, Tang S, Xia L, et al: Ectopic expression of MiR-125a inhibits the proliferation and metastasis of hepatocellular carcinoma by targeting MMP11 and VEGF. PLoS One 7: e40169, 2012.

14. Karsy M, Arslan E and Moy F: Current progress on understanding microRNAs in glioblastoma multiforme. Genes Cancer 3: 3-15, 2012.

15. Osanto S, Qin Y, Buermans HP, et al: Genome-wide microRNA expression analysis of clear cell renal cell carcinoma by next generation deep sequencing. PLoS One 7: e38298, 2012.

16. Jing Q, Huang S, Guth S, et al: Involvement of microRNA in AU-rich element-mediated mRNA instability. Cell 120: 623-634, 2005

17. Guo S, Bai H, Megyola CM, et al: Complex oncogene dependence in microRNA-125a-induced myeloproliferative neoplasms. Proc Natl Acad Sci USA 109: 16636-16641, 2012.

18. Zaman MS, Shahryari V, Deng G, et al: Up-regulation of microRNA-21 correlates with lower kidney cancer survival. PLoS One 7: e31060, 2012.

19. Zhao A, Li G, Péoc'h M, Genin C and Gigante M: Serum miR-210 as a novel biomarker for molecular diagnosis of clear cell renal cell carcinoma. Exp Mol Pathol 94: 115-120, 2013.

20. Slaby O, Redova M, Poprach A, et al: Identification of MicroRNAs associated with early relapse after nephrectomy in renal cell carcinoma patients. Genes Chromosomes Cancer 51: 707-716, 2012.

21. Redova M, Poprach A, Nekvindova J, et al: Circulating miR-378 and miR-451 in serum are potential biomarkers for renal cell carcinoma. J Transl Med 10: 55, 2012.

22. Khella HW, Bakhet M, Allo G, et al: miR-192, miR-194 and miR-215: a convergent microRNA network suppressing tumor progression in renal cell carcinoma. Carcinogenesis 34: 2231-2239, 2013

23. Murata K, Furu M, Yoshitomi H, et al: Comprehensive microRNA analysis identifies miR-24 and miR-125a-5p as plasma biomarkers for rheumatoid arthritis. PLoS One 8: e69118, 2013.

24. Coppola N, Potenza N, Pisaturo M, et al: Liver microRNA hsa-miR-125a-5p in HBV chronic infection: correlation with HBV replication and disease progression. PLoS One 8: e65336, 2013.

25. Nishida N, Mimori K, Fabbri M, et al: MicroRNA-125a-5p is an independent prognostic factor in gastric cancer and inhibits the proliferation of human gastric cancer cells in combination with trastuzumab. Clin Cancer Res 17: 2725-2733, 2011.

26. Hashiguchi Y, Nishida N, Mimori K, et al: Down-regulation of miR-125a-3p in human gastric cancer and its clinicopathological significance. Int J Oncol 40: 1477-1482, 2012.

27. Pazo Cid RA and Antón A: Advanced HER2-positive gastric cancer: current and future targeted therapies. Crit Rev Oncol Hematol 85: 350-362, 2013.

28. Smith MB, Reardon J and Olson EM: Pertuzumab for the treatment of patients with previously untreated HER2-positive metastatic breast cancer. Drugs Today (Barc) 48: 713-722, 2012.

29. Sendur MA, Aksoy S and Altundag K: Pertuzumab in HER2-positive breast cancer. Curr Med Res Opin 28: 1709-1716, 2012. 